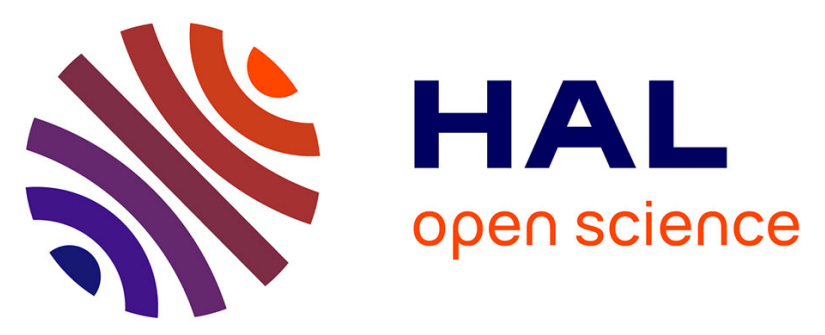

\title{
A non-additive repulsive contribution in an equation of state: The development for homonuclear square well chains equation of state validated against Monte Carlo simulation
}

Thi-Kim-Hoang Trinh, Jean-Philippe Passarello, Jean-Charles de Hemptinne, Rafael Lugo, Véronique Lachet

\section{To cite this version:}

Thi-Kim-Hoang Trinh, Jean-Philippe Passarello, Jean-Charles de Hemptinne, Rafael Lugo, Véronique Lachet. A non-additive repulsive contribution in an equation of state: The development for homonuclear square well chains equation of state validated against Monte Carlo simulation. Journal of Chemical Physics, 2016, 144, pp.124902. 10.1063/1.4944068 . hal-01339980

\author{
HAL Id: hal-01339980 \\ https://hal.science/hal-01339980
}

Submitted on 30 Jun 2016

HAL is a multi-disciplinary open access archive for the deposit and dissemination of scientific research documents, whether they are published or not. The documents may come from teaching and research institutions in France or abroad, or from public or private research centers.
L'archive ouverte pluridisciplinaire HAL, est destinée au dépôt et à la diffusion de documents scientifiques de niveau recherche, publiés ou non, émanant des établissements d'enseignement et de recherche français ou étrangers, des laboratoires publics ou privés. 


\title{
A NON ADDITIVE REPULSIVE CONTRIBUTION IN AN EQUATION OF STATE: THE DEVELOPMENT FOR HOMONUCLEAR SQUARE WELL CHAINS EQUATION OF STATE VALIDATED AGAINST MONTE CARLO SIMULATION
}

\author{
Thi-Kim-Hoang TRINH ${ }^{a, b}$, Jean-Philippe PASSARELLO ${ }^{b, *}$, \\ Jean-Charles DE HEMPTINNE ${ }^{a}$, Rafael LUGO ${ }^{a}$, Veronique LACHET ${ }^{a}$ \\ ${ }^{\text {a }}$ IFP Energies nouvelles, 1 et 4 avenue de Bois-Préau, 92852 Rueil-Malmaison, France \\ ${ }^{\mathrm{b}}$ Laboratoire de Science des Procédés et des Matériaux (LSPM), Université Paris 13, CNRS, 99 \\ avenue Jean-Baptiste Clément, 93430 Villetaneuse, France
}

\begin{abstract}
This work consists of the adaptation of a non-additive hard sphere theory inspired by Malakhov and Volkov, Polym. Sci. Ser. A. 2007;49(6):745-756 to a square-well chain. Using the thermodynamic perturbation theory, an additional term is proposed that describes the effect of perturbing the chain of square well spheres by a non-additive parameter. In order to validate this development, NPT Monte Carlo simulations of thermodynamic and structural properties of the non-additive square well (NASW) for a pure chain and a binary mixture of chains are performed. Good agreements are observed between the compressibility factor originating from the theory and those from molecular simulations.
\end{abstract}

Keywords: Square-well potential, non-additive parameter, Monte Carlo simulation, compressibility factor, inter - segment distribution function

\section{Introduction}

Computation of realistic phase equilibria is of central importance in chemical engineering and more specifically for designing unit operations. In this domain, the equations of state play a major role allowing to deal with a wide range of mixtures in a broad range of pressures and temperatures. A good equation of state is capable of calculating and in the best case of predicting phase equilibria. This is the reason why theoretically rooted equations of state (based on statistical mechanics) such as $\mathrm{SAFT}^{1,2}$ are increasingly used in engineering problems. 
Certain systems remain however difficult to model such as small molecule (e.g. gases) + solvents. A non-zero adjustable binary parameter must be used in order to reach experimental precision. From now on, the common practice is to use the so-called $\mathrm{k}_{\mathrm{ij}}$ i.e. the binary parameter acting on energy of the dispersion term $: \varepsilon_{i j}=\sqrt{\varepsilon_{i i} \cdot \varepsilon_{j j}}\left(1-k_{i j}\right)$. Far more rarely, the effect on phase equilibria computation of binary parameter $1_{\mathrm{ij}}$ on cross diameter i.e. $\sigma_{i j}=\frac{\sigma_{i i}+\sigma_{j j}}{2}\left(1-l_{i j}\right)$ was explored ${ }^{3}$. Only limited number of equations of state were developed to account for this possible non-additivity effect mainly for spherical ${ }^{4-11}$ or hard chain ${ }^{12,13}$ molecules. To the best of our knowledge no equation of state was developed for non-additive attractive chain molecules.

Our general goal is to propose an adequate implementation of a non-additive diameter in an engineering but theoretically rooted EOS such as PC-SAFT. As a first step, in a procedure similar to that followed by Gross and Sadowski ${ }^{14,15}$, we will first consider square well chain fluids as prototype fluids. The main goal of the work reported in this paper is to develop a non-additive Square Well Chain Equation of state that applies to small molecule + solvent systems. Extension to PC-SAFT will be presented in the next article.

This paper is presented as follows. First, the general description of square well chains equation of state based on statistical mechanics is presented. Next, the development of a nonadditive term for square well chains is shown with in particular the determination of the intersegment distribution functions of square-well chains. Finally, the approach is validated against Monte Carlo molecular simulations for the pure chains and for the mixtures of square wells chains.

\section{Development of non-additive Square Well Chain Equation of state}

\subsection{General expression of the equation of state}

The interaction potential between segments $i$ and $j$ of two non-additive square-well homonuclear chain molecules is defined as:

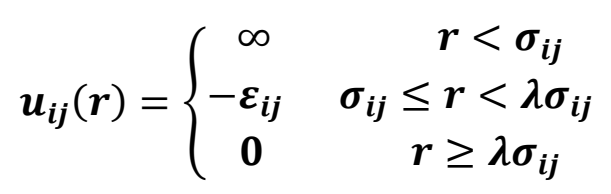

With

$$
\sigma_{i j}=\frac{\sigma_{i}+\sigma_{j}}{2}\left(1-l_{i j}\right)
$$


Notice that $1_{\mathrm{ii}}=1_{\mathrm{jj}}=0$; non-additivity implies non-zero $\mathrm{l}_{\mathrm{ij}}$.

The equation of state derived from the above potential may be obtained by using perturbation techniques that start by subdividing the potential into a reference and a perturbation part:

$$
u_{i j}(r)=u_{i j}^{r e f}(r)+u_{i j}^{p e r t}(r)
$$

In standard procedures, one would choose the reference part as repulsive. This would lead to deal with non-additive hard chains as reference fluid for which little is known; in particular analytical expression of inter-segment distribution functions are unknown and simulation data for these functions are not available whereas they are needed to compute the perturbation part.

So, rather than starting from the very beginning with the development of a new equation of state, we decided to base our work on the proposal of Malakhov and Volkov ${ }^{16}$, who developed a model of non-additive chains of hard spheres using a specifically designed perturbation. Doing so, the reference term is chosen as the additive potential i.e. for which $1_{\mathrm{ij}}=0$. The reference potential is written:

$$
u_{i j}(r)=\left\{\begin{array}{cc}
\infty & r<\sigma_{i j} \\
-\varepsilon_{i j} & \sigma_{i j} \leq r<\lambda \sigma_{i j} \\
0 & r \geq \lambda \sigma_{i j}
\end{array}\right.
$$

With

$$
\sigma_{i j}=\frac{\sigma_{i}+\sigma_{j}}{2}
$$

This is the potential of usual square-well chain (SWC) molecules for which equations of state are available. ${ }^{14}$ This potential and its parameters are denoted with SWC superscript in the rest of the paper. Several authors have investigated the use of a square well reference that lead to the Square Well chains equation of state ${ }^{17-20}$.

The perturbation part is simply defined as the difference between the non-additive and additive potentials and denoted NAS (Non - Additive Segments). In terms of Helmholtz free energy one obtains : 


$$
\frac{A}{N k T}=\frac{A^{S W C}}{N k T}+\frac{A^{N A S}}{N k T}
$$

where $\mathrm{N}$ is the total number of molecules, $\mathrm{k}$ is the Boltzmann constant, and $\mathrm{T}$ is the absolute temperature. $A^{S W C}$ denotes the system energy in additive interactions ${ }^{14}$ i.e. ordinary square-well chain fluids (SWC).

The contribution $A^{N A S}$ (NAS = Non - Additive Segments) is the perturbation term that acts as a correction to the additive behavior. In the same way as in the work of Malakhov and Volkov $^{16}$, this term is evaluated here at the first order :

$$
\frac{A^{N A S}}{N k T}=\frac{1}{2} \rho \sum_{i} \sum_{j} x_{i} m_{i} x_{j} m_{j} \int 4 \pi r^{2} d r g_{i j}^{S W C}(r) \beta u_{i j}^{N A S}(r)
$$

Where $g_{i j}^{S W C}(r)$ represents the intersegment distribution function of a fluid of ordinary square-well chains. In equation (5) $\mathrm{x}_{\mathrm{i}}, \mathrm{x}_{\mathrm{j}}$ are molar fractions of molecule $i$ and $j$ respectively; $\mathrm{m}_{\mathrm{i}}$, $\mathrm{m}_{\mathrm{j}}$ are the number of constitutive segments or the length chain of molecule $i$ and $j ; \rho$ is the total molecular density and $\beta=\frac{1}{k T}$.

\subsection{Computation of the perturbed contribution of the Helmholtz free energy}

Following again Malakhov and Volkov ${ }^{16}$, an explicit expression of $A^{N A S}$ is obtained by making a limited development at first order of $u_{i j}^{N A S}$ at the neighborhood of the additive potential (using the Taylor series).

$$
u_{i j}^{N A S}(r)=\left(\frac{\partial u_{i j}(r)}{\partial \sigma_{i j}}\right)_{\sigma_{i j}=\sigma_{i j}^{S W C} \text { or } l_{i j}=0}\left(\sigma_{i j}-\sigma_{i j}^{S W C}\right)+\cdots
$$

Where the diameter for the additive case is written : $\sigma_{i j}^{S W C}=\frac{\sigma_{i}+\sigma_{j}}{2}$.

In order to evaluate the derivative, we used the function $e^{-\beta u_{i j}(r)}$. One has : 


$$
\frac{d e^{-\beta u_{i j}(r)}}{d \sigma_{i j}}=-e^{-\beta u_{i j}(r)} \beta \frac{d u_{i j}(r)}{d \sigma_{i j}}
$$

And recalling that $\sigma_{i j}=\sigma_{i j}^{S W C}\left(1-l_{i j}\right)$, we can deduce then :

$$
\beta u_{i j}^{N A S}(r)=e^{\beta u_{i j}^{S W C}(r)}\left(\frac{d e^{-\beta u_{i j}(r)}}{d \sigma_{i j}}\right)_{l_{i j}=0} \sigma_{i j}^{S W C} l_{i j}
$$

Taking advantage of the shape of $u_{i j}(r)$ (equation 3 ) that is such that $e^{-\beta u_{i j}(r)}$ can be expressed in terms of Heaviside step functions, we find:

$$
e^{-\beta u_{i j}}=\left[H\left(r-\sigma_{i j}\right)-H\left(r-\lambda \sigma_{i j}\right)\right] e^{\beta \varepsilon_{i j}}+H\left(r-\lambda \sigma_{i j}\right)
$$

The derivative of which is written as:

$$
\frac{d e^{-\beta u_{i j}(r)}}{d \sigma_{i j}}=e^{\beta \varepsilon_{i j}}\left(\frac{d H\left(r-\sigma_{i j}\right)}{d \sigma_{i j}}-\frac{d H\left(r-\lambda \sigma_{i j}\right)}{d \sigma_{i j}}\right)+\frac{d H\left(r-\lambda \sigma_{i j}\right)}{d \sigma_{i j}}
$$

Which can be written in terms of Dirac functions:

$$
\frac{d e^{-\beta u_{i j}(r)}}{d \sigma_{i j}}=e^{\beta \varepsilon_{i j}}\left(-\delta\left(r-\sigma_{i j}\right)+\lambda \delta\left(r-\lambda \sigma_{i j}\right)\right)-\lambda \delta\left(r-\lambda \sigma_{i j}\right)
$$

Therefore, we have:

$$
\left(\frac{d e^{-\beta u_{i j}^{S W C}(r)}}{d \sigma_{i j}}\right)_{l_{i j}=0}=e^{\beta \varepsilon_{i j}}\left(-\delta\left(r-\sigma_{i j}^{S W C}\right)+\lambda \delta\left(r-\lambda \sigma_{i j}^{S W C}\right)\right)-\lambda \delta\left(r-\lambda \sigma_{i j}^{S W C}\right)
$$

Recall that we need to find the expression of free energy according to the equation (5) Combining equations (5), (6) and (12) we get : 


$$
\begin{aligned}
\frac{A^{N A S}}{N k T}=2 \pi \rho & \sum_{i} \sum_{j} x_{i} x_{j} m_{i} m_{j} \int_{0}^{\infty} r^{2} g_{i j}^{S W C}(r) \times \sigma_{i j}^{S W C} \times l_{i j} \times e^{\beta u_{i j}^{S W C}(r)} \\
& \times\left(-e^{\beta \varepsilon_{i j}}\left[\delta\left(r-\sigma_{i j}^{S W C}\right)-\lambda \delta\left(r-\lambda \sigma_{i j}^{S W C}\right)\right]+\lambda \delta\left(r-\lambda \sigma_{i j}^{S W C}\right)\right) d r
\end{aligned}
$$

This expression can be further simplified using standard arguments making use of cavity function $^{60}$ defined by $y_{i j}^{S W C}(r)=g_{i j}^{S W C}(r) e^{\beta u_{i j}^{S W C}(r)}$. This function is continuous at $r=\sigma_{i j}$ :

$$
\begin{aligned}
\frac{A^{N A S}}{N k T}=-2 \pi \rho & \sum_{i} \sum_{j} x_{i} x_{j} m_{i} m_{j} \times \sigma_{i j}^{S W C} \times l_{i j} \\
& \times\left(\sigma_{i j}^{S W C 2} y_{i j}^{S W C}\left(\sigma_{i j}^{S W C}\right) e^{\beta \varepsilon_{i j}}-\left(\lambda \sigma_{i j}^{S W C}\right)^{2} y_{i j}^{S W C}\left(\lambda \sigma_{i j}^{S W C}\right) e^{\beta \varepsilon_{i j}}\right. \\
& \left.+\left(\lambda \sigma_{i j}^{S W C}\right)^{2} \lambda y_{i j}^{S W C}\left(\lambda \sigma_{i j}^{S W C}\right)\right)
\end{aligned}
$$

Where the cavity functions are evaluated either at the upper side of the limit (indicated by "+"), or at the lower side of the limit (marked with "-") :

$$
\begin{aligned}
& y_{i j}^{S W C}\left(\sigma_{i j}^{S W C}\right)=g_{i j}^{S W C}\left(\sigma_{i j}^{S W C+}\right) e^{-\beta \varepsilon_{i j}} \\
& y_{i j}^{S W C}\left(\lambda \sigma_{i j}^{S W C}\right)=g_{i j}^{S W C}\left(\lambda \sigma_{i j}^{S W C-}\right) e^{-\beta \varepsilon_{i j}}
\end{aligned}
$$

It leads to:

$$
\begin{aligned}
\frac{A^{N A S}}{N k T}=-2 \pi \rho & \sum_{i} \sum_{j} x_{i} x_{j} m_{i} m_{j} \sigma_{i j}^{S W C 3} l_{i j}\left[g_{i j}^{S W C}\left(\sigma_{i j}^{S W C+}\right)-\lambda^{3} g_{i j}^{S W C}\left(\lambda \sigma_{i j}^{S W C-}\right)\right. \\
& \left.+e^{-\beta \varepsilon_{i j} \lambda^{3} g_{i j}^{S W C}}\left(\lambda \sigma_{i j}^{S W C-}\right)\right]
\end{aligned}
$$

This expression requires having average inter - segment distribution functions at contact $g_{i j}^{S W C}\left(r=\sigma_{i j}^{S W C+}\right)$ and at limit $g_{i j}^{S W C}\left(r=\lambda \cdot \sigma_{i j}^{S W C-}\right)$ for a chain of spheres interacting via an 
additive square well potential. This is the subject of the next section.

\subsection{Determination of inter segment distribution function $\boldsymbol{g}_{\boldsymbol{i} i}^{\mathrm{SWC}}(\boldsymbol{r})$}

We must now determine the inter-segment distribution function $g_{i j}^{\mathrm{SWC}}(r)$. In this work, we used the suggestion of Paredes et $\mathrm{al}^{22}$ who proposed to link $g_{i j}^{\mathrm{SWC}}(r)$ (between 2 segments of 2 different chains) to the radial distribution function of disconnected spheres (called $g_{S, S}$ ) and the inter-segment distribution function of dimers (called $g_{D, D}$ ). Expressions for this latter radial distribution exist in the literature as a function of $\eta=\rho v_{m}, v_{m}$ being the molecular hard core volume and $T^{*}=k T / \varepsilon=1 / \beta \varepsilon$.

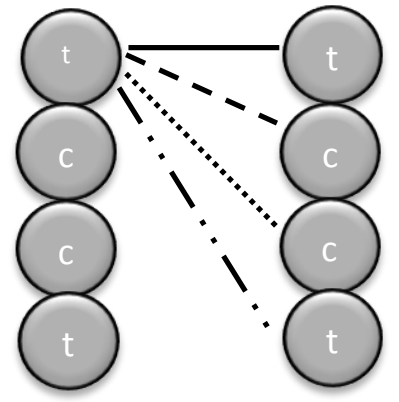

Chain A Chain B

Figure 1: Interactions between chain A and chain B

For two identical chains containing $m$ segments, there are 4 interactions between terminal segments, $(m-2)^{2}$ interactions between internal segments and $4(m-2)$ interactions between a terminal segment and an internal segment. Therefore, we obtain the average inter-segment distribution function between 2 identical molecules as (cf. Figure 1) :

$$
g_{i j}=\frac{4 g_{T T}+4(m-2) g_{I T}+(m-2)^{2} g_{I I}}{m^{2}}
$$

Where $g_{T T}$ is the radial distribution function between two terminal segments; $g_{I T}$ is the radial distribution function between an internal segment and external terminal segment; $g_{I I}$ is the radial distribution function between two internal segments and $\mathrm{m}$ is the chain length.

According to Paredes et al. $^{22}$, the inter-segment functions are supposed to depend on 
accessible surfaces. In their work, the relations between the inter-segment distribution functions and $\mathrm{g}_{\mathrm{D}, \mathrm{D}}$ and $\mathrm{g}_{\mathrm{S}, \mathrm{S}}$ are written as:

$$
\begin{gathered}
g_{T T}=g_{D, D}(19) \\
g_{I T}=\frac{3}{2} g_{D D}-\frac{1}{2} g_{S S}(20) \\
g_{I I}=2 g_{D D}-g_{S S}
\end{gathered}
$$

These results are consistent with the study of Chiew et al. ${ }^{23,24}$ who worked on the site-site correlation function of 4-mer hard chain by using the Percus-Yevick approximation. It is also compatible with the Flory theory of Hall et al. ${ }^{25-27}$ and it can be extended to the square well potential (with $\lambda=1.5$ ).

For the general case, we must deal with molecules having different numbers of segments $m_{i}$ and $m_{j}$. Computing the average inter-segment distribution function is performed by a weighted average of the number of interactions:

$$
g_{i j}=\frac{4 g_{T_{i} T_{j}}+2\left(m_{i}-2\right) g_{I_{i} T_{j}}+2\left(m_{j}-2\right) g_{I_{j} T_{i}}+\left(m_{j}-2\right)\left(m_{i}-2\right) g_{I_{i} I_{j}}}{m_{i} m_{j}}
$$

Based on homonuclear chains relations, we make the following approximation :

$$
\begin{gathered}
\boldsymbol{g}_{T_{i} T_{j}}(\boldsymbol{\eta}) \approx \boldsymbol{g}_{T \boldsymbol{T}}(\boldsymbol{\eta})(23) \\
\boldsymbol{g}_{\boldsymbol{I}_{\boldsymbol{i}} \boldsymbol{I}_{j}}(\boldsymbol{\eta}) \approx \boldsymbol{g}_{\boldsymbol{I I}}(\boldsymbol{\eta})(24) \\
\boldsymbol{g}_{T_{\boldsymbol{i}} \boldsymbol{I}_{j}}(\boldsymbol{\eta}) \approx \boldsymbol{g}_{T_{\boldsymbol{j}} \boldsymbol{I}_{\boldsymbol{i}}}(\boldsymbol{\eta}) \approx \boldsymbol{g}_{I T}(25)
\end{gathered}
$$

In order to determine the inter-segment distribution function, it is necessary to have the 
inter-segment distribution function of square well spheres and dimers as a function of packing fraction and temperature. The values of $g_{S, S}$ and $g_{D, D}$ at contact $\mathrm{x}=\mathrm{r} / \sigma=1$ and at $\mathrm{x}=\lambda^{-}=1.5^{-}$ were fitted using the following empirical expression:

$$
\mathrm{g}\left(\boldsymbol{\eta}, \boldsymbol{T}^{*}\right)=\mathrm{g}(\boldsymbol{\eta}, \infty)+\left[g\left(\mathbf{0}, \boldsymbol{T}^{*}\right)-g(\mathbf{0}, \infty)\right] \frac{1+a \cdot \boldsymbol{\eta}+b \cdot \boldsymbol{\eta}^{2}}{1+c \cdot \boldsymbol{\eta}+d \cdot \boldsymbol{\eta}^{2}+e \cdot \boldsymbol{\eta}^{3}}
$$

The form of this expression was partially motivated by noticing from molecular simulation data of Tavares et $\mathrm{al}^{28}$ that at high packing fraction $(\eta>0.3-0.4)$ the square-well fluid behaves closely to the hard fluid: in those conditions we have $\mathrm{g}\left(\eta, \mathrm{T}^{*}\right) \approx \mathrm{g}\left(\eta, \mathrm{T}^{*}=\infty\right)$. Also this expression obeys the high temperature limit $\left(\mathrm{g}\left(\eta, \mathrm{T}^{*}\right) \rightarrow \mathrm{g}(\eta, \infty)\right.$ when $\left.\mathrm{T}^{*} \rightarrow \infty\right)$ and the low density limit $\left(\mathrm{g}\left(\eta, \mathrm{T}^{*}\right) \rightarrow \mathrm{g}(0, \infty)\right.$ when $\left.\eta \rightarrow 0\right)$. Coefficients $\mathrm{a}, \mathrm{b}, \mathrm{c}, \mathrm{d}$ and e are purely empirical and obtained by fitting simulation data (see table 1 below).

The expression of the hard fluid inter-segment distribution is of a Carnahan and Starling type:

$$
\mathrm{g}(\boldsymbol{\eta}, \infty)=\frac{A+B \cdot \boldsymbol{\eta}+C \cdot \boldsymbol{\eta}^{2}+D \cdot \boldsymbol{\eta}^{3}}{(\mathbf{1}-\boldsymbol{\eta})^{3}}
$$

Coefficients A, B, C and D are known for spheres and dimers at contact. Those values are re-used in this work. At $x=\lambda^{-}=1.5^{-}$, the values of these coefficients were determined by fitting available simulation data (see table 1).

The inter-segment distribution at zero packing fraction was put in the following form:

$$
\mathrm{g}\left(\mathbf{0}, \boldsymbol{T}^{*}\right)=\boldsymbol{e}^{\alpha+\frac{\beta}{T^{*+}}\left(\frac{\gamma}{T^{*}}\right)^{2}}
$$

The coefficients $\alpha, \beta$ and $\gamma$ are known for spheres at contact. In the other cases, they were adjusted on simulation data.

In Table 1, the available data of inter-segment distribution functions that were used for fitting unknown coefficients in equations (26-28) are detailed. They were obtained by 3 different methods. The first method is an NVT Monte Carlo simulation where temperature, the volume and the number of particles of the system are imposed. The second method is a Monte Carlo NPT simulation where pressure is fixed instead of volume). The third method is called BYG integral 
equation. This method has been solved for many short-ranged potentials such as hard sphere ${ }^{29,30}$, square well $^{31}$ and Lennard-Jones ${ }^{32,33}$ fluids. See the original articles for more details. This method is approximate and the resulting values are not as reliable as simulation data. However, such data are useful in conditions where no simulation data exist.

As mentioned above, in this development we use the value of $\lambda$ equal to 1.5 which is the most current width in square well potential where data are more abundant in the literature ${ }^{34-36}$. Extension of our model to other values of $\lambda$ can be done if the corresponding simulation data are available.

As it appears in table 1 and from a literature analysis, most data are available at temperature $\mathrm{T}^{*}$ equal or higher than 1.5 .

Table 1: Summary of conditions of Monte Carlo simulation for fitting and for validation

\begin{tabular}{|c|c|c|c|c|c|}
\hline & $\mathbf{m}$ & $\eta$ & $\mathbf{T}^{*}$ & Method & Authors \\
\hline \multirow[t]{8}{*}{ For fitting } & \multirow{4}{*}{1} & $0.05 \leq \eta \leq 0.45$ & $1.5,2,3,10$ & NVT & Largo et $\mathrm{al}^{37}$ \\
\hline & & $0.01 \leq \eta \leq 0.5$ & $1.5,2,3,4$ & NVT & Tavares et $\mathrm{al}^{28}$ \\
\hline & & $0.26 \leq \eta \leq 0.42$ & $1,2,4, \infty$ & NVT & $\begin{array}{c}\text { Henderson et } \\
\mathrm{al}^{38}\end{array}$ \\
\hline & & $0.15 \leq \eta \leq 0.37$ & $1,2,3$ & NVT & Scarfe et $\mathrm{al}^{39}$ \\
\hline & \multirow{4}{*}{2} & $0 \leq \eta \leq 0.4$ & $1.5,2$ & BGY Equation & Lipson et $\mathrm{al}^{35}$ \\
\hline & & $0.01 \leq \eta \leq 0.5$ & $1.5,2,3,4$ & NVT & Tavares et $\mathrm{al}^{28}$ \\
\hline & & $\eta=0$ & & & Taylor $^{40}$ \\
\hline & & $0 \leq \eta \leq 0.4$ & $\infty$ & $\begin{array}{c}\text { BGY Equation } \\
\text { and NVT }\end{array}$ & $\begin{array}{l}\text { Taylor and } \\
\text { Lipson }^{41}\end{array}$ \\
\hline \multirow{6}{*}{$\begin{array}{l}\text { For validation: } \\
\text { pure } \\
\text { compound data }\end{array}$} & 4 & $0 \leq \eta \leq 0.35$ & 1.5 & BGY Equation & Lipson et $\mathrm{al}^{36}$ \\
\hline & $6,8,16$ & $0 \leq \eta \leq 0.3$ & 1.5 & BGY Equation & Lipson et $\mathrm{al}^{34}$ \\
\hline & 4 & $0.05 \leq \eta \leq 0.45$ & \multirow{3}{*}{1.5} & \multirow{3}{*}{ NVT } & \multirow{3}{*}{ Tavares et $\mathrm{al}^{28}$} \\
\hline & 8 & \multirow{2}{*}{$0.36 \leq \eta \leq 0.45$} & & & \\
\hline & 16 & & & & \\
\hline & 4 & $0 \leq \eta \leq 0.5$ & 1.5 & NPT & This work \\
\hline
\end{tabular}




\begin{tabular}{|c|c|c|c|c|c|}
\hline $\begin{array}{c}\text { For validation: } \\
\text { mixtures data }\end{array}$ & $\begin{array}{c}1+4 \\
\mathrm{x}_{1}=0.5\end{array}$ & \multirow{2}{*}{$0.05 \leq \eta \leq 0.5$} & $1.5,2,3$ & NVT & Paredes et al \\
\cline { 2 - 4 } & $2+8$ & & & & \\
& $\mathrm{x}_{1}=0.5$ & & & & \\
\hline
\end{tabular}

All coefficient values used in equations (26-28) may be found in table 2.

Table 2. Parameter values for use in equations (26-28)

\begin{tabular}{|c|c|c|c|c|}
\hline & $\mathbf{g}_{\text {SS }}$ at $\mathbf{x}=\mathbf{1}^{+}$ & $\mathbf{g}_{\text {SS }}$ at $\mathbf{x}=\mathbf{1 . 5}^{-}$ & $\mathbf{g}_{\text {DD }}$ at $\mathbf{x = 1} \mathbf{1}^{+}$ & $\mathbf{g}_{\text {DD }}$ at $\mathbf{x}=\mathbf{1 . 5}^{-}$ \\
\hline $\mathbf{A}$ & 1 & 0.542 & 1 & 0.7181 \\
\hline $\mathbf{B}$ & -0.5 & 0.06137 & -2.3993 & -0.6696 \\
\hline $\mathbf{C}$ & 0 & 0 & -0.4537 & -3.6023 \\
\hline $\mathbf{D}$ & 0 & 0 & 3.0762 & 4.7213 \\
\hline $\mathbf{a}$ & -6.4228863 & -5.4190153 & 1.65546909 & -3.5876021 \\
\hline $\mathbf{b}$ & 8.54442269 & 6.79903564 & -4.6437027 & 4.15933189 \\
\hline $\mathbf{c}$ & -1.6134866 & -1.5638579 & 6.67813868 & 0.4981693 \\
\hline $\mathbf{d}$ & 5.82989458 & 9.94915946 & 45.6261314 & 30.7918644 \\
\hline $\mathbf{e}$ & 13.284929 & 1.75799648 & 56.5520302 & 1.92703553 \\
\hline $\boldsymbol{\alpha}$ & 1 & 1 & -0.6675 & -0.2939 \\
\hline $\boldsymbol{\beta}$ & 0 & 0 & 2.2625 & 1.4688 \\
\hline $\boldsymbol{\gamma}$ & 0 & 0 & 0 & 0.64475 \\
\hline
\end{tabular}

Examples of fitting at $\mathrm{T}^{*}=1.5$ are shown in Figure 2. A good fitting is observed. 

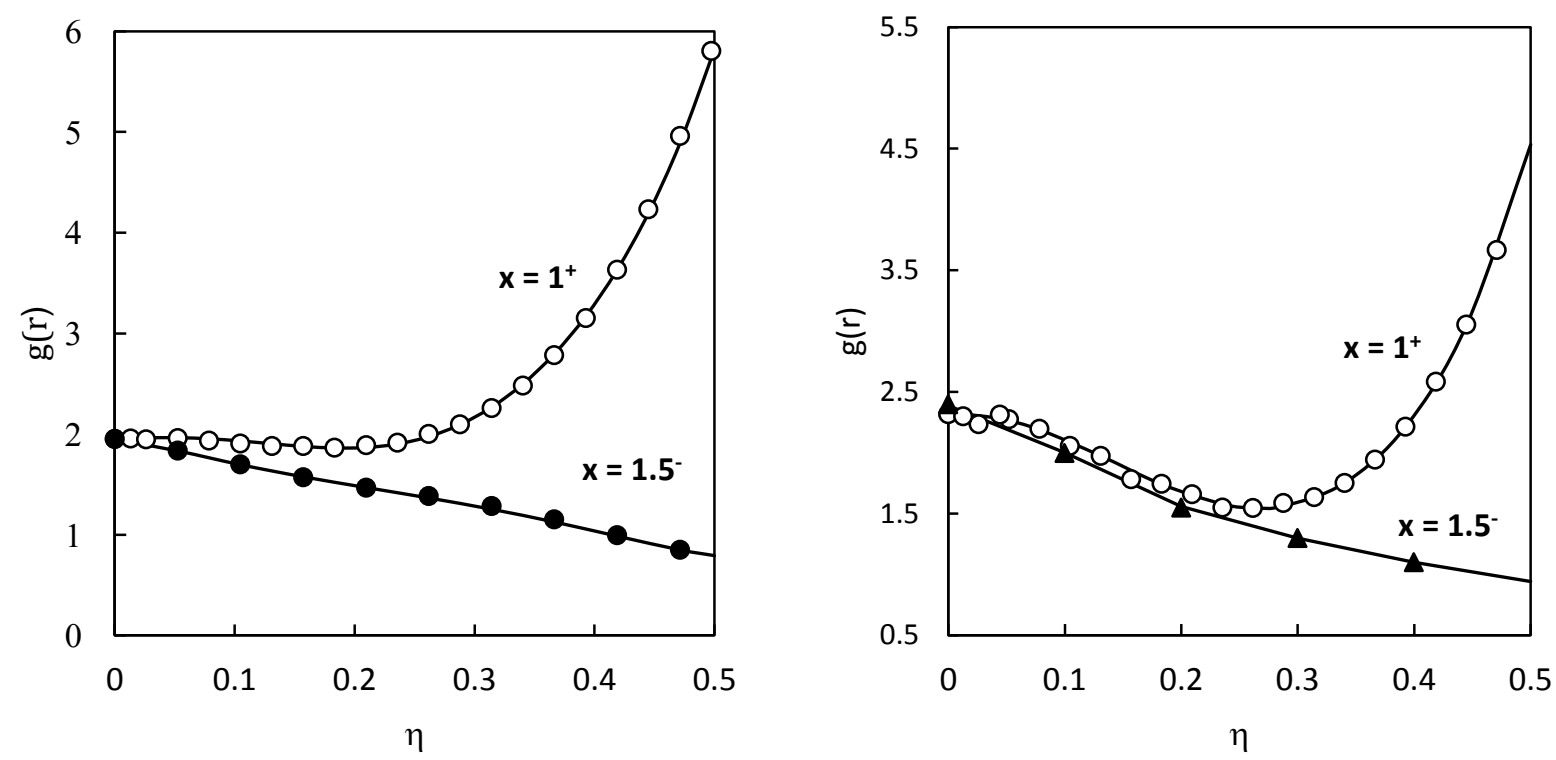

Figure 2: Fitting inter-segment distribution functions of square well spheres (on the left) and square well dimers (on the right) at $\mathrm{x}=\lambda^{-}=1.5^{-}$and $\mathrm{T}^{*}=1.5$. Full line (-) are $\mathrm{g}(\mathrm{r})$ calculated from the fitted expressions (26-28) and symboles are $\mathrm{g}(\mathrm{r})$ originating from $(\mathbf{\Delta})$ Lipson et $\mathrm{al}^{32},(\mathbf{O}$ Largo et al. $^{37}$ and $(\bigcirc)$ Tavares et $\mathrm{al}^{28}$.

Validation is shown in the next section.

\section{Monte Carlo simulation data}

In this work, we used Monte Carlo simulation to validate the approach by comparing, for both the simulation and the model the inter-segment distribution function for pure chains and the compressibility factor for mixtures of chains. The MC simulations were performed with a standard NPT algorithm using $\mathrm{N}=250$ particles at different reduced pressures $\left(P^{*}=P \sigma^{3} / \varepsilon_{i j}\right)$ and reduced temperature $\left(T^{*}=k T / \varepsilon_{i j}\right)$. The average properties are computed during a production run lasting 500 million Monte Carlo steps, one step corresponding to a single Monte Carlo move. Before each production run, a preliminary run of 50 million Monte Carlo steps is carried out to achieve equilibrium. The number of Monte Carlo steps may change depending on the convergence. In the case of square-well interactions, a spherical cutoff equal to half of the simulation box was used while classical tail corrections were employed ${ }^{43}$. For the intramolecular terms, the bonding is fixed with tangent spheres. There is neither bending nor torsion between two segments. The different Monte Carlo moves and their corresponding attempt probabilities used during the simulations are 
molecular translation (20\%), molecular rotation (20\%), regrowth with configurational bias (59\%) and volume change (1\%). The amplitude of translations, rotations and volume changes was adjusted during the simulation to achieve an acceptance ratio of $40 \%$ for these moves.

\subsection{Pure chains of square wells}

For each simulation, the radial distribution functions $g(r)$ for a pure square well chain are given directly. In NPT, in order to determine the $\mathrm{g}(\mathrm{r})$, it is necessary to get the histogram that represents the average number of particles whose distance from a given particle lies in the interval $(r, r+d r)$. After, the radial distribution function is calculated by this expression:

$$
g(r+1 / 2 d r)=\frac{h(r)}{\frac{N}{V} \times \frac{4}{3} \pi\left((r+d r)^{3}-r^{3}\right)}
$$

Where $\mathrm{h}(\mathrm{r})$ is the histogram; $\mathrm{N}$ is total number of particles in the system; $\mathrm{V}$ is the volume of simulation box.

The MC simulation conditions are $\mathrm{m}=4, \sigma=1$ and $\mathrm{T}^{*}=1.5$. Data were acquired for $\mathrm{P}^{*} / \mathrm{T}^{*}$ ranging from 0.001 to 1.5 . The data are reported in supplementary section in table S1.

\subsection{Mixtures of chains of square wells}

For mixtures of chains of square-well, the same approach using Monte Carlo simulation method was employed. In the simulation box, we defined a number of particles for each type of molecules. And the property that we consider is the compressibility factor. The compressibility is calculated from following equation:

$$
Z=\frac{P}{\rho k T}
$$

Where $\mathrm{P}, \rho, \mathrm{T}, v$ is the pressure, the molecular density, the temperature and the molar volume of system respectively, $k$ is Boltzmann constant.

As mentioned above, a standard NPT algorithm is used for these calculations. It means that the pressure $\mathrm{P}$, the number of particles $\mathrm{N}$ (for each type of molecules in the simulation box) and 
the temperature $\mathrm{T}$ of the system are imposed. The computation gives a density that yields directly the compressibility factor using Equation (29).

The input parameters are the reduced temperature $\mathrm{T}^{*}\left(T^{*}=k_{B} T / \varepsilon\right.$ where $\varepsilon$ is the dispersive energy, the reduced pressure $\mathrm{P}^{*}\left(P^{*}=\sigma^{3} P / \varepsilon\right.$, where $\sigma$ is the diameter of the particle, this property is reduced in the mixture of 2 different particles) and the number of particles of each kind, as shown in table 3 . In case of mixture of chains, each particle has the same dispersive energy $\varepsilon_{i j}$. We present usually the compressibility factor $\mathrm{Z}$ as a function of the compacity $\eta$ with:

$$
\eta=\frac{\pi}{6} \rho=\sum_{i} x_{i} m_{i} \sigma_{i}^{3}
$$

The density, and thus the molar volume are obtained directly from the statistical averages performed over the different Monte Carlo configurations. For example in the post-treatment, the molecular density is determined by:

$$
\rho=\frac{N}{\langle V\rangle}
$$

Where $N$ is the number of particles in the box that is a fixed input (see table 3 ) in our case and $\langle V\rangle$ is the average molar volume. The MC simulation conditions for chain mixtures are summarized in Table 4.

Non-zero values of the non-additive parameter $l_{\mathrm{ij}}$ are taken into account by the use of the modified Lorentz-Berthelot combining rule:

$$
\sigma_{i j}=\frac{\sigma_{i}+\sigma_{j}}{2}\left(1-l_{i j}\right)
$$

In fact, in the MC simulation, we impose the diameter values $\boldsymbol{\sigma}_{\boldsymbol{i}}, \boldsymbol{\sigma}_{\boldsymbol{j}}$ of each component. We choose a value of $1_{\mathrm{ij}}$, so the cross diameter is calculated by using Equation (32) then imposed in MC simulation. 
Table 3: Summary of the different MC simulations performed on mixtures.

\begin{tabular}{|c|c|c|c|c|c|c|c|}
\hline $\mathbf{T} *$ & $\mathbf{P} * / \mathbf{T}$ & $\mathbf{N}_{\mathbf{1}}$ & $\mathbf{m}_{\mathbf{1}}$ & $\mathbf{N}_{\mathbf{2}}$ & $\mathbf{m}_{\mathbf{2}}$ & $\boldsymbol{\sigma}_{\mathbf{2}} / \boldsymbol{\sigma}_{\mathbf{1}}$ & $\mathbf{l}_{\mathbf{1 2}}$ \\
\hline 30 & $0.02-0.8$ & 100 & 1 & 100 & 4 & 1.5 & $0,0.1$ \\
\hline 1.5 & $0.02-0.8$ & 100 & 1 & 100 & 4 & 1.5 & $0,0.5,0.1$ \\
\hline 1 & $0.02-0.8$ & 100 & 1 & 100 & 4 & 1.5 & 0.1 \\
\hline 0.75 & $0.02-0.8$ & 100 & 1 & 100 & 4 & 1.5 & 0.1 \\
\hline 1.5 & $0.02-0.8$ & 100 & 1 & 100 & 4 & 3 & $0,0.1$ \\
\hline 1.5 & $0.02-0.8$ & 50 & 1 & 150 & 4 & 1.5 & $0,0.1$ \\
\hline 1.5 & $0.02-0.8$ & 100 & 2 & 100 & 5 & 1.5 & $0,0.1$ \\
\hline 1.5 & $0.02-0.8$ & 100 & 2 & 100 & 5 & 3 & $0,0.1$ \\
\hline
\end{tabular}

In fact, here we only consider the positive values of $1_{12}$. The geometric combining rule seems more adapted than the arithmetic one. Therefore it is mostly expected that $l_{12}>0$. We considered the results of compressibility factor $\mathrm{Z}$ of chain mixtures mainly for the cases $1_{12}=0$ and $1_{12}=0.1$. The results of molecular simulations for these mixtures are presented in table $\mathrm{S} 2$ in supplementary material.

\section{Validation of Square Wells Chains EoS against Monte Carlo simulation results}

In this section, two properties are validated against Monte Carlo (MC) simulation. At first, the inter-segment distribution functions at contact and at $r=\lambda \sigma$ (with $\lambda=1.5$ ) for the pure chains is presented. Comparisons with molecular simulation results available in the literature are also provided. At second, the compressibility factor for mixtures of square-well chains is validated by MC simulation.

\subsection{Validation of inter-segment distribution function}

In Figures 3 and 4, our approach to calculate the distribution functions for chains is compared to the simulation reported by Lipson et al. ${ }^{35,36}$ and Tavares et al. ${ }^{28}$ for $\mathrm{m}=4,6,8$ and 16. On the left of Figure 3 and Figure 4, the radial distribution function is evaluated at contact $(\mathrm{r}=$ $\sigma)$ and at $(r=\lambda \sigma)$ for different compacities for chain length $\mathrm{m}=4$ and a reduced temperature of 1.5. Comparable figures for the other studied chain lengths $(m=6,8,16)$ are provided in Appendix B. We see that the inter-segment distribution function, which is about 4 for ideal gas and rises slightly for longer chains, first decreases as the density increases, passes through a minimum and 
then increases at higher densities. Our model represents correctly the qualitative behavior obtained by molecular simulation.

We observe that, at medium and high density, a reasonable agreement is obtained between the relation proposed for the calculation of $g\left(\sigma^{+}\right)$and $g\left(\lambda \sigma^{-}\right)$and the values calculated by Lipson and $\mathrm{al}^{34-36}$ and Tavares et $\mathrm{al}^{28}$ for pure compounds and Paredes et $\mathrm{al}^{42}$ for mixtures. At low densities the agreement is less good: as a consequence virial coefficients are not expected to be well predicted (see below).

However, the free energy $A^{N A S}$ corresponding to the non-additive term in Equation (17) depends on the inter-segment distribution function $g(r)$ and on the density $\rho$ or the reduced density $\rho^{*}$ that is a function of compacity $\eta\left(\rho^{*}=\rho \sum_{i} x_{i} m_{i} \sigma_{i}^{3}=\frac{6 \eta}{\pi}\right)$. A good modeling of $A^{N A S}$ may be obtained if the products of these two terms $(\rho \cdot g(r))$ is represented correctly and especially $\rho . g(r=$ $\lambda . \sigma^{-}$) at low $\mathrm{T}^{*}$ and high $\lambda$ (this term is magnified by $\lambda^{3} \cdot\left(\mathrm{e}^{1 / \mathrm{T}^{*}}-1\right)$ in equation (17)). Such quantity is shown on the right part of Figures $3 a$ and $3 b$ for pure 4-mer.
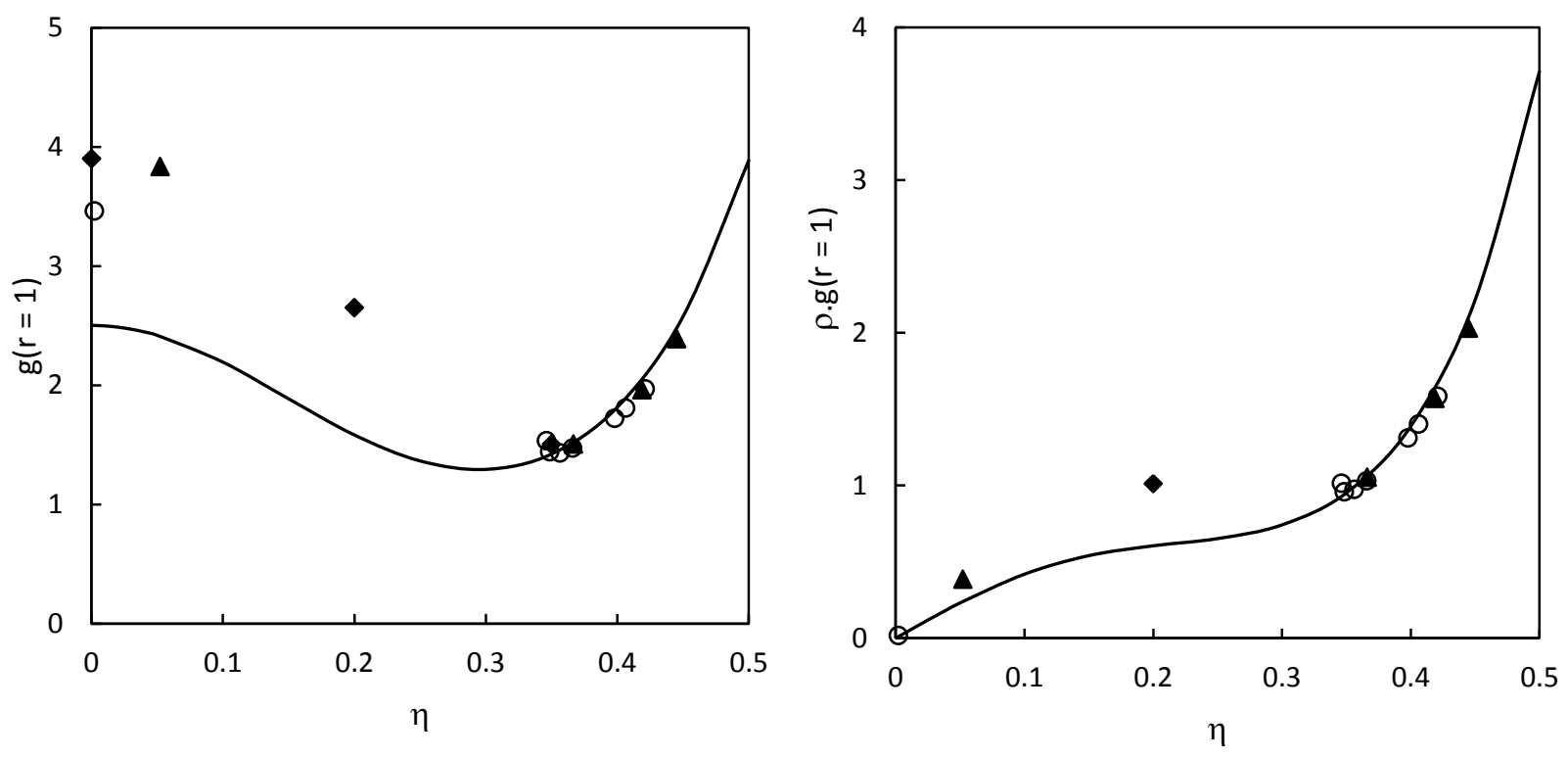

Figure 3a: Values of inter-segment distribution function at contact calculated in this work and taken from literature: $(\diamond)$ Lipson et al. ${ }^{35,36}$ and $(\boldsymbol{\Delta})$ Tavares et al. ${ }^{28}$ in case $\mathrm{m}=4$ at $\mathrm{T}^{*}=1.5$. In this work, simulation results (o), calculation by our model (一) 

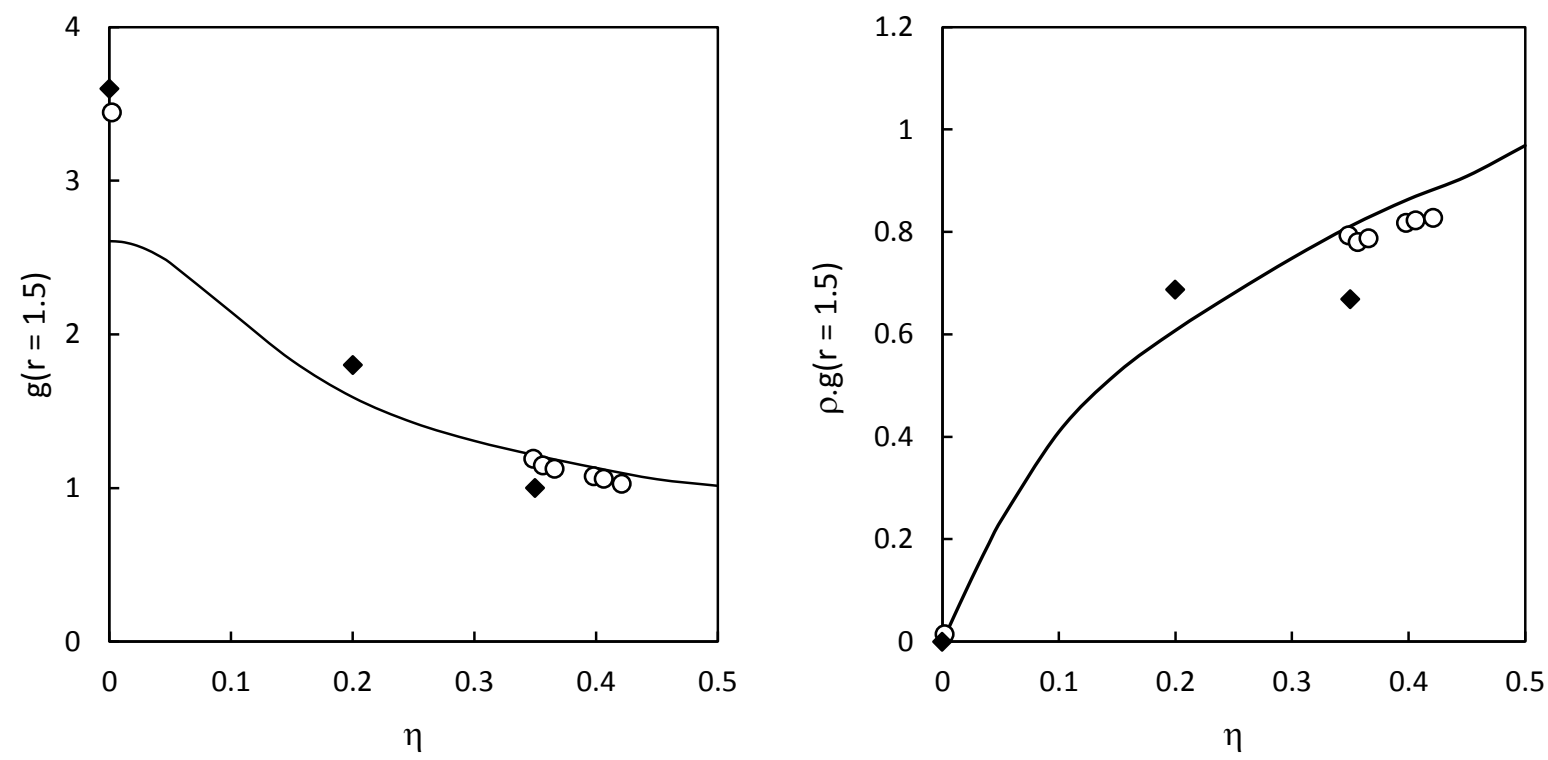

Figure 3b: Values of inter-segment distribution function at $r=\lambda \cdot \sigma^{-}$(with $\left.\lambda=1.5\right)$ calculated in this work and taken from literature: $(\diamond)$ Lipson et al. ${ }^{35,36}$ in case $\mathrm{m}=4$ at $\mathrm{T}^{*}=1.5$; simulation results (o); calculation by our model (-)
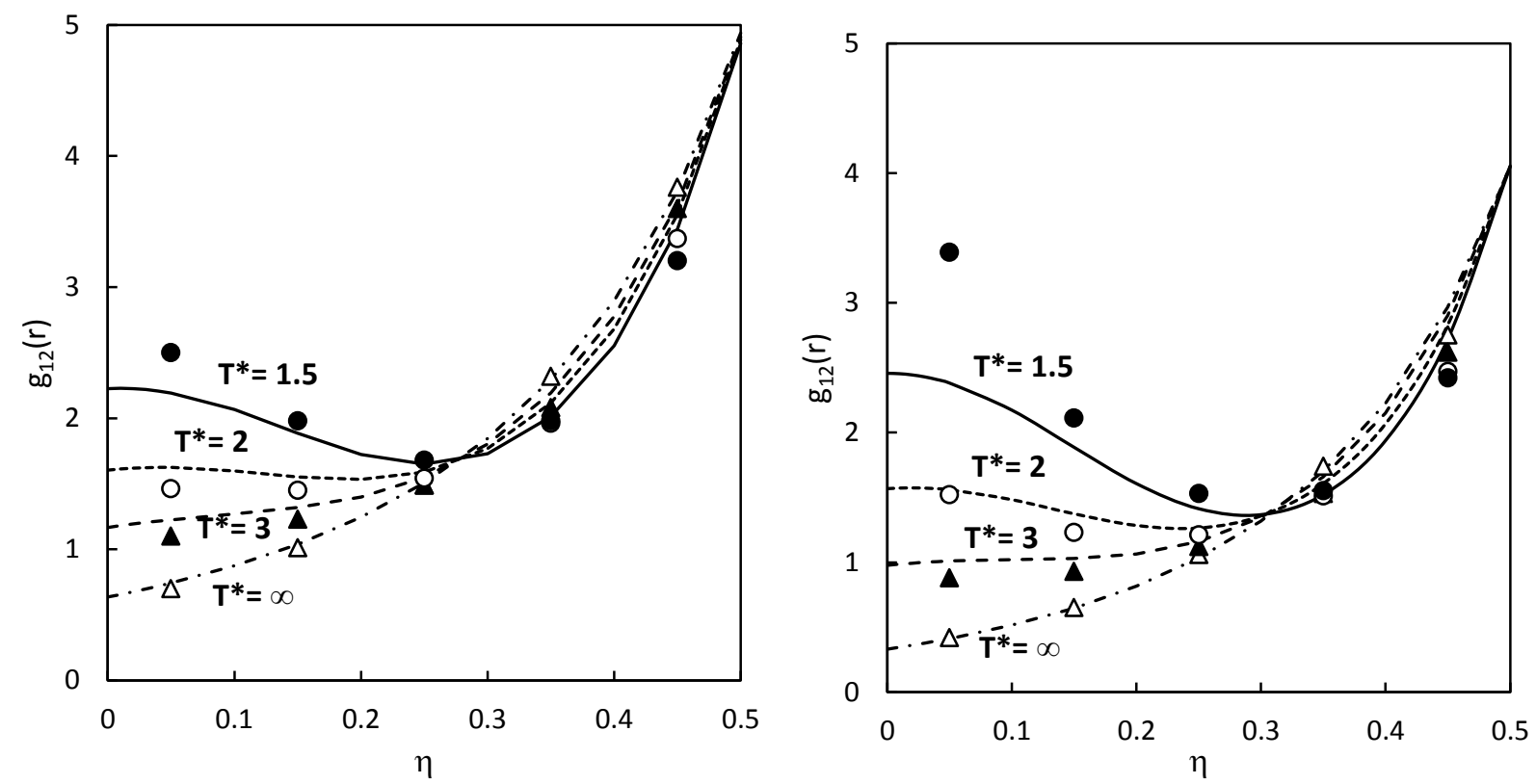

Figure 4: Values of inter-segment distribution function at contact calculated by our model (-); symbols are for data taken from Paredes et $\mathrm{al}^{42}$. Mixtures considered here are: left plot: $\mathrm{m}_{1}=1, \mathrm{~m}_{2}$ 
$=4, \sigma_{1}=\sigma_{2}=1$ and $\mathrm{x}_{1}=0.5$; right plot: $\mathrm{m}_{1}=2, \mathrm{~m}_{2}=8, \sigma_{1}=\sigma_{2}=1$ and $\mathrm{x}_{1}=0.5$

A good agreement is found between the theory and the simulations whatever the compacity. In view of all the approximation made, the above results allow us validating the expression of the site-site distribution function (22) to compute free energy.

\subsection{Validation of compressibility factor}

After the validation of the inter-segment distribution functions for the pure square-well chains, we compare the compressibility factor $\mathrm{Z}$ of binary mixture of square well chains calculated from our EoS to the ones originating from our Monte Carlo simulations. Consistently with our free energy the compressibility factor $\mathrm{Z}$ is calculated as a sum of two terms:

$$
\mathrm{Z}=\mathrm{Z}^{\mathrm{SWC}}+\mathrm{Z}^{\mathrm{NAS}}
$$

Here for $\mathrm{Z}^{\mathrm{SWC}}$ we have chosen the model of Gross and Sadowski ${ }^{14} \cdot \mathrm{Z}^{\mathrm{NAS}}$ is obtained from equation (17) using standard thermodynamic relations. As a preliminary step it is interesting to put in light the conditions where the NAS term is significant in comparison with the SWC term. For this purpose, on figure $5, \mathrm{Z}^{\mathrm{SWC}}$ and $\mathrm{Z}^{\mathrm{NAS}}$ were plotted for mixtures $\mathrm{m}_{1}=1, \mathrm{~m}_{2}=4, \sigma_{1}=1, \sigma_{2}=$ $1.5, \mathrm{x}_{1}=0.5$ at different temperatures $\mathrm{T}^{*}$ ranging from 0.75 to $\infty$. From this figure it seems that the NAS term become significant for $\eta>0.2-0.3$. This term appears less depend on temperature than SWC term. 


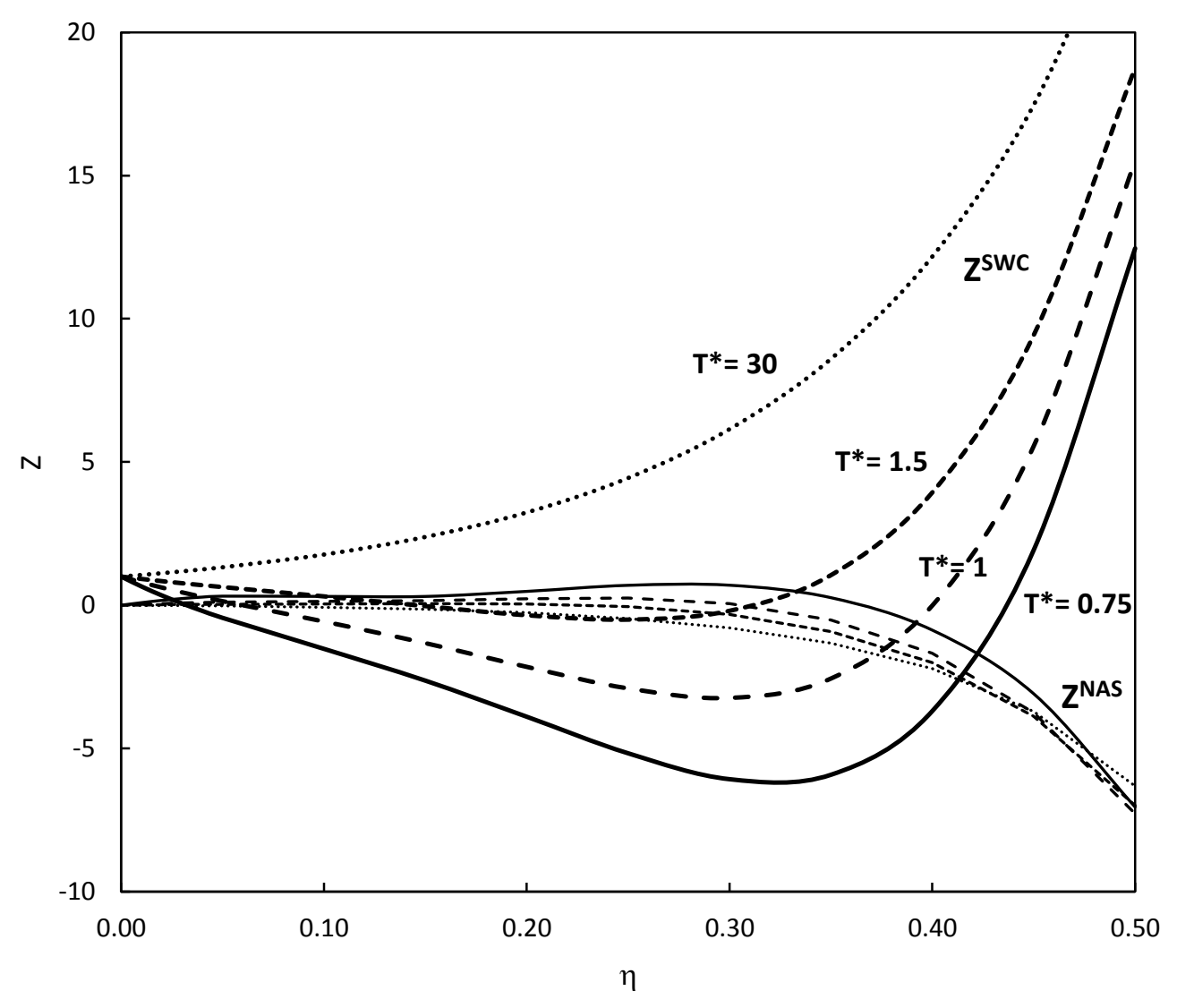

Figure 5. Plot of $\mathrm{Z}^{\mathrm{SWC}}$ and $\mathrm{Z}^{\mathrm{NAS}}$ in function of compacity at different temperatures. The mixture considered is in the following conditions: $\mathrm{m}_{1}=1, \mathrm{~m}_{2}=4, \sigma_{1}=1, \sigma_{2}=1.5, \mathrm{x}_{1}=0.5$ and $1_{12}=$ 0.1

This is also clearly seen on figure 6 where we compare our model (with and without NAS term) to simulation data. Thanks to NAS term a good agreement with simulation data is generally obtained, but one may also observe deterioration at low temperatures. From this figure, it can be inferred that our model should not be used at temperature below 0.75 . 

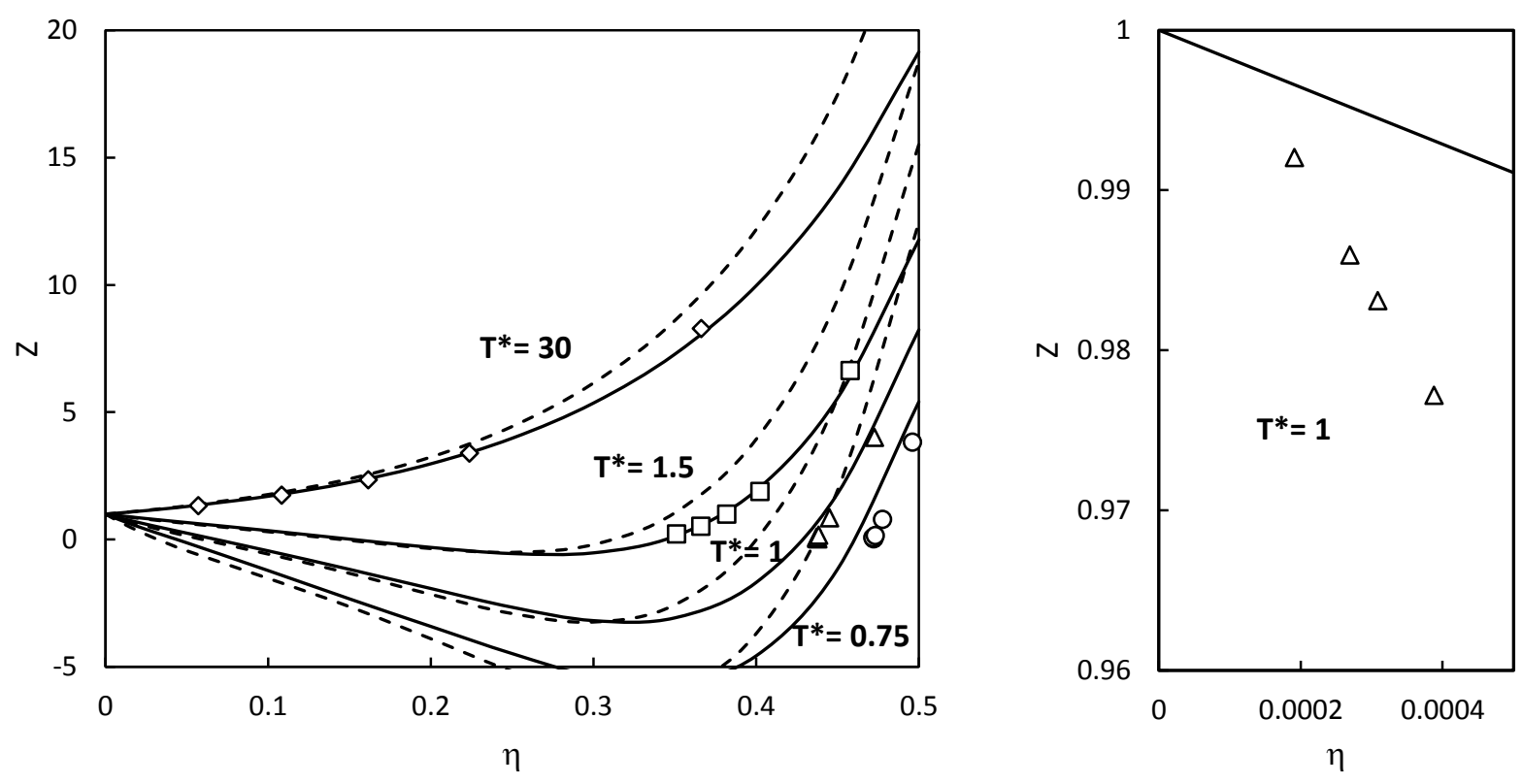

Figure 6. Comparison between our model and simulation data. The mixture considered is in the following conditions: $\mathrm{m}_{1}=1, \mathrm{~m}_{2}=4, \sigma_{1}=1, \sigma_{2}=1.5$ and $\mathrm{x}_{1}=0.5 ; 1_{12}=0.1$. Symbols are for our simulation data; (-) full model (eq. 34); (----) $\mathrm{Z}^{\mathrm{SWC}}$.

At low density (right part of figure 6) $\mathrm{Z}$ is predicted by our model within $2 \%$ error in comparison with simulation data. As expected and already noticed above the second virial coefficient is not well predicted (see the differences in the slopes).

In the next figures we test the influence of several parameters on the predictions of our model: $1_{\mathrm{ij}}$ (see figure 7), number fraction $\mathrm{x}_{1}$ (see figure 8), diameter ratio (see figure 9-10) and chains lengths (see figure 10).

As a general comment, we may conclude that our model reproduces qualitatively and quantitatively well the behavior of the fluid mixtures when the above-cited parameters are varied.

More specifically, the evolution of compressibility factor at high compacity (when NAS term is important) is well captured by the model when $l_{12}$ is varied from 0 to 0.1 as may be seen on the example in figure 7.

As may be shown on figure 8 , the influence of the number fraction appears well taken into account by our model. 

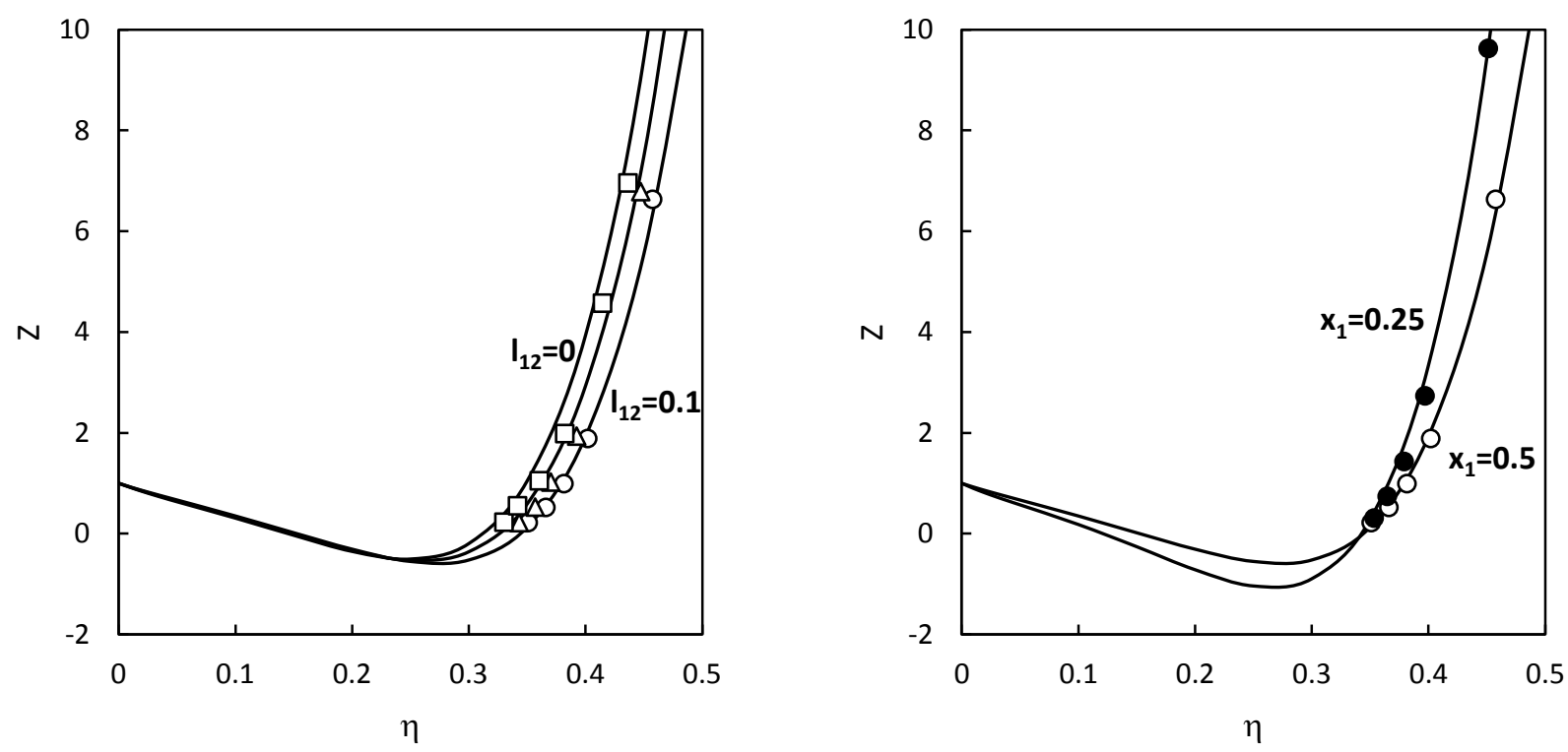

Figure 7: Comparison of the compressibility Figure 8: Comparison of the compressibility factor $\mathrm{Z}$ calculated by square-well chains EoS factor $\mathrm{Z}$ calculated by square-well chains EoS at and issued from molecular simulation for the different composition. The mixtures conditions mixture: $\mathrm{m}_{1}=1, \mathrm{~m}_{2}=4, \sigma_{1}=1, \sigma_{2}=1.5$ and $\mathrm{x}_{1}=$ are: $\mathrm{m}_{1}=1, \mathrm{~m}_{2}=4, \sigma_{1}=1, \sigma_{2}=1.5$ and $\mathrm{l}_{12}=0.1$ 0.5. Different $\mathrm{l}_{\mathrm{ij}}$ are considered: $0(\square), 0.05(\triangle)$ The symbols denote the Monte Carlo simulation and $0.1(\bigcirc)$. The solid lines are the predictions of data. The solid lines are the predictions of the the equation of state of square well chains. equation of state of square well chains.

In the next figures 9-10, we investigate the effect of the mixture asymmetry on the prediction of the model. Asymmetry is tested through two parameters: size ratio between the two compounds and chain lengths. Here again our model appears to compute reasonably well the compressibility factor if compared to simulation data. 

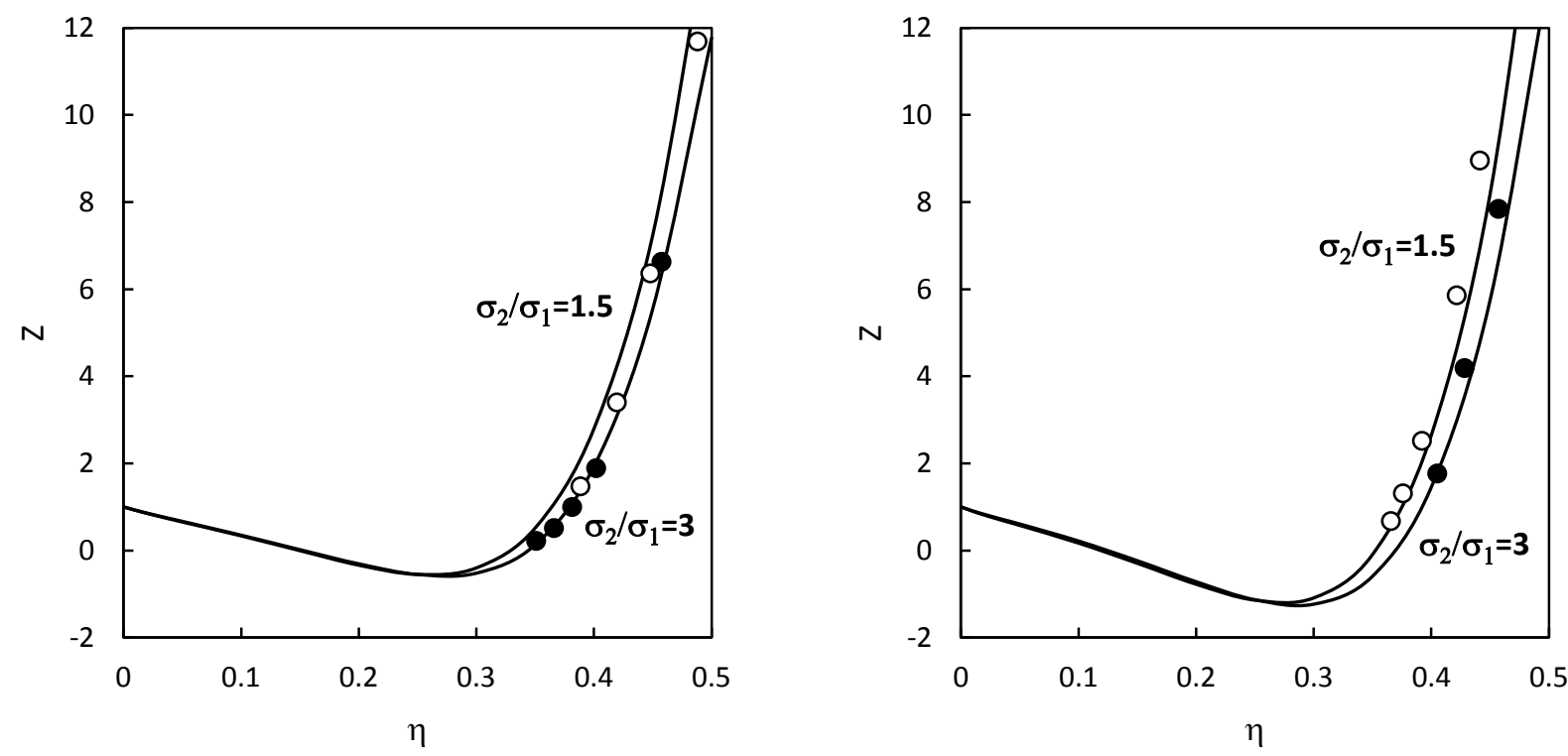

Figure 9: Comparison of the compressibility Figure 10: Comparison of the compressibility factor $\mathrm{Z}$ calculated by square-well chains EoS factor $\mathrm{Z}$ calculated by square-well chains EoS and and issued from molecular simulation for issued from molecular simulation for different different diameter ratio. The conditions of the diameter ratio. The conditions of the mixture are: mixture are: $\mathrm{m}_{1}=1, \mathrm{~m}_{2}=5, \mathrm{x}_{1}=0.5, \mathrm{~T}^{*}=1.5$ and $\mathrm{m}_{1}=2, \mathrm{~m}_{2}=5, \mathrm{x}_{1}=0.5, \mathrm{~T}^{*}=1.5$ and $\mathrm{1}_{12}=0.1$. $1_{12}=0.1$. The symbols denote the Monte Carlo The symbols denote the Monte Carlo simulation simulation data and the solid lines are the data and the solid lines are the predictions of the predictions of the equation of state of square equation of state of square well chains. well chains.

From all the observations made above, it may be concluded that the predictions of compressibility factor by our model appear satisfactory and reliable in a rather wide range of temperature $\left(\mathrm{T}^{*}>0.75\right)$, composition, sizes and non-additivity $\left(1_{12}<0.1\right)$. This result was obtained even if crude hypotheses were made in the development of the model.

\section{Conclusions}

The main target of this paper is to develop a physically-meaningful predictive approach for introducing a repulsive correction in an equation of state. This is done by using the perturbation theory, applied on a reference consisting of chains of square well molecules. The approach is 
validated against molecular simulation.

The correction works well at high density, but more substantial deviations are observed at very low density. Three possible paths are suggested for further improvement:

- refitting inter-segment distribution functions after acquisition of new molecular simulation data, especially at lower temperature

- revising equations (19-20) to predict better inter-segment distribution function at low density and low temperature

- a re-mapping of the $\mathrm{l}_{\mathrm{ij}}$ parameter as suggested in the work of Parricaud ${ }^{44}$.A modification in the non-additive parameter may be needed to allow better predictions. In his development for non-additive hard-sphere systems, Parricaud ${ }^{44}$ proposed to replace the non-additive theoretical terms contained $\sigma_{i j}^{2}\left(\sigma_{i j}^{N A S}-\sigma_{i j}\right)$ by $\left(\sigma_{i j}^{N A S 3}-\sigma_{i j}^{3}\right)$. This modification allows a correct calculation of the second virial coefficient but to the best of our knowledge the second virial coefficient of non-additive square well chains is unknown. This should be investigated in a future work.

\section{Author Information}

Corresponding author

*E-mail: : Jean-Philippe.Passarello@lspm.cnrs.fr

Tel : +33149403406

\section{Acknowledgements}

We would like to thank the financial support of Tuck Foundation through IFP Energies Nouvelles for this research. 


\section{Appendix: The inter-segment distribution functions of pure chains of square}

wells
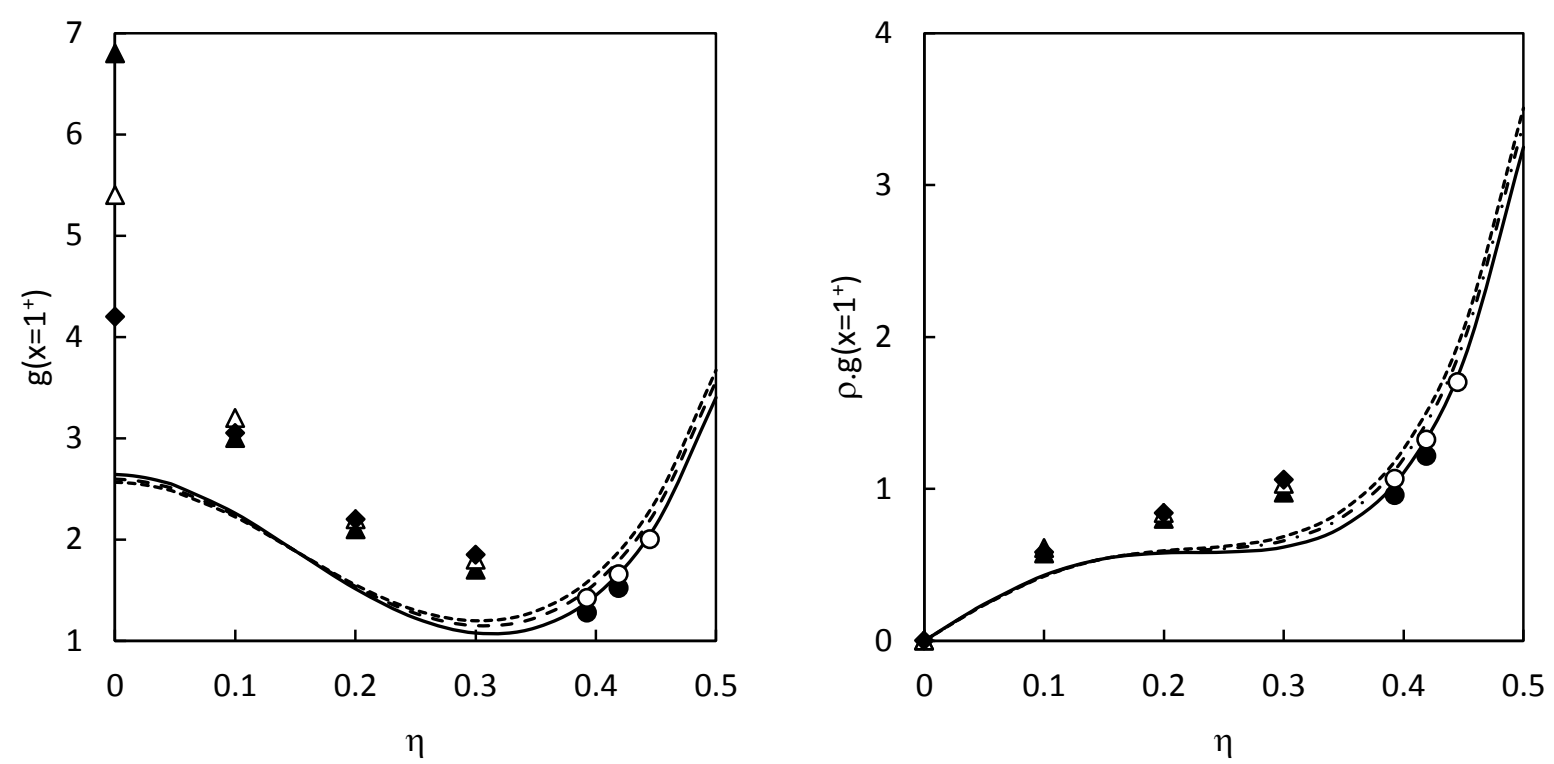

Figure A1: Values of inter-segment distribution function at contact calculated and taken from literature in case $\mathrm{T}^{*}=1.5$ and $\mathrm{m}=6$ : $(\diamond)$ data from Lipson et al. ${ }^{32,33}(-)$, our model; $\mathrm{m}=8:(\triangle)$ data from Lipson et al. ${ }^{32,33}$, (O) data from Tavares et al. ${ }^{29},\left({ }^{---}\right)$our model; $\mathrm{m}=16$ : $(\boldsymbol{\Delta})$ data from Lipson et al. ${ }^{32,33},(\mathbf{O})$ data from Tavares et al. ${ }^{29},(\cdots \cdots)$ our model.
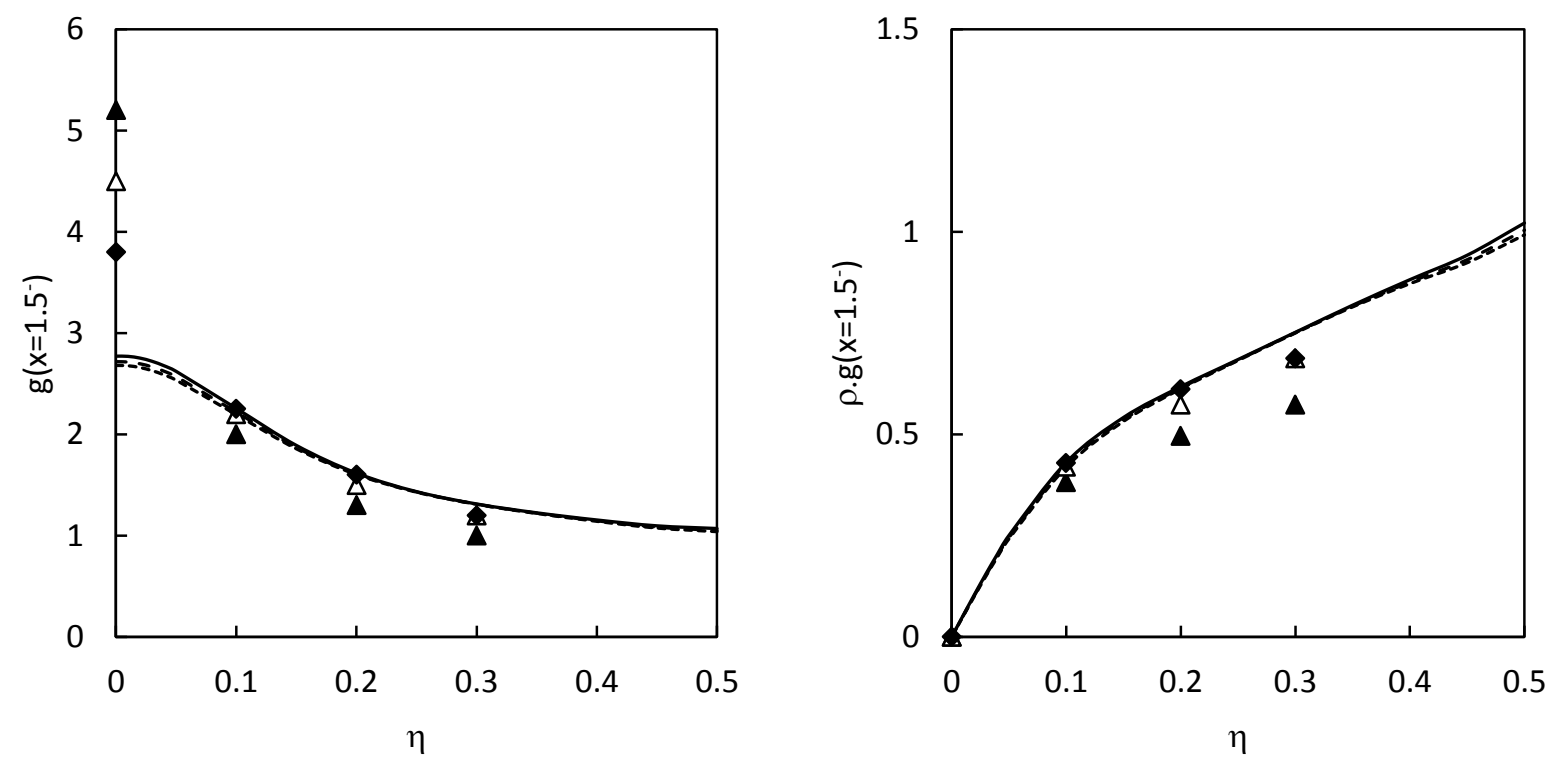

Figure A2: Values of inter-segment distribution function at $\lambda=1.5$ calculated and taken from literature in case $\mathrm{T}^{*}=1.5$ and $\mathrm{m}=6$ : $(\diamond)$ data from Lipson et al. ${ }^{32,33}(-)$, our model; $\mathrm{m}=8:(\triangle)$ 
data from Lipson et al. ${ }^{32,33},\left({ }^{---}\right)$our model; $m=16:(\boldsymbol{\Delta})$ data from Lipson et al. ${ }^{32,33},(\cdots \cdots)$ our model.

\section{References}

1. Chapman WG, Gubbins KE, Jackson G, Radosz M. SAFT: Equation-ofstate solution model for associating fluids. Fluid Phase Equilib. 1989;52(0):31-38.

2. Chapman WG, Gubbins KE, Jackson G, Radosd M. New Reference Equation of State for Associating Liquids. Ind Eng Chem Res. 1990;29:1709-1721.

3. Nguyen T-B, de Hemptinne J-C, Creton B, Kontogeorgis GM. Improving GC-PPC-SAFT equation of state for LLE of hydrocarbons and oxygenated compounds with water. Fluid Phase Equilib. 2014;372:113-125.

4. Adams DJ, McDonald IR. Fluids of hard spheres with nonadditive diameters. J Chem Phys. 1975;63(5):1900.

5. Dickinson E. On the thermodynamics of polydisperse systems of non-additive hard particles. Chem Phys Lett. 1976;66(3):1-5.

6. Gazzillo D. Fluid-fluid phase separation of nonadditive hard-sphere mixtures as predicted by integral-equation theories. J Chem Phys. 1991;95(6):4565.

7. Jagannathan K, Reddy G, Yethiraj A. Integral equation theory for symmetric nonadditive hard sphere mixtures. J Phys Chem B. 2005;109(14):6764-6768.

8. Rovere M, Pastore G. Fluid-fluid phase separation in binary mixtures of asymmetric nonadditive hard spheres. J Phys Condens Matter. 1994;6(23A):A163-A166.

9. Saija F, Giaquinta P V. Entropy and Fluid - Fluid Separation in Nonadditive Hard-Sphere Mixtures: The Asymmetric Case. J Phys Chem B. 1998;106:2035-2040.

10. Santos A, López De Haro M, Yuste SB. Equation of state of nonadditive d-dimensional hard-sphere mixtures. J Chem Phys. 2005;122(2):0245141-02451415.

11. Hammawa H, Hamad EZ. A simple model for size non-additive mixtures. J Chem Soc, Faraday Trans,. 1996;92(24):4943-4949. 
12. Abu-Sharkh BF, Hamad EZ. Simulation and Model Development for the Equation of State of Self-Assembling Nonadditive Hard Chains. Macromolecules. 2000;33(4):1345-1350.

13. Abu-Sharkh BF, Hamad EZ. Investigation of the Microstructure of Micelles Formed by Hard-Sphere Chains Interacting via Size Nonadditivity by Discontinuous Molecular Dynamics Simulation. Langmuir. 2004;20(1):254-259.

14. Gross J, Sadowski G. Application of perturbation theory to a hard-chain reference fluid: an equation of state for square-well chains. Fluid Phase Equilib. 2000;168:183-199.

15. Gross J, Sadowski G. Perturbed-Chain SAFT: An Equation of State Based on a Perturbation Theory for Chain Molecules. Ind Eng Chem Res. 2001;40(4):1244-1260.

16. Malakhov AO, Volkov V V. Phase behavior of polymer mixtures with nonadditive hardsphere potential. Polym Sci Ser A. 2007;49(6):745-756.

17. Banaszak M, Chiew YC, Radosz M. Thermodynamic perturbation theory: Sticky chains and square-well chains. Phys Rev E. 1993;48(5):3760-3765.

18. Adidharma H, Radosz M. Prototype of an Engineering Equation of State for Heterosegmented. Ind Eng Chem Res. 1998;37(11):4453-4462.

19. Gil-Villegas A, Galindo A, Whitehead PJ, Mills SJ, Jackson G, Burgess AN. Statistical associating fluid theory for chain molecules with attractive potentials of variable range. $J$ Chem Phys. 1997;106(10):4168.

20. Tavares FW, Chang J, Sandler SI. A completely analytic equation of state for the squarewell chain fluid of variable well width. Fluid Phase Equilib. 1997;140:129-143.

21. Hansen JP, McDonald IR. Theory of Simple Liquids; 3rd Edition. London, England: Academic Press; 2005.

22. Lyra Paredes ML, dos Reis RA, Tavares FW. Inner segment radial distribution functions at contact point for chain-like molecules. J Mol Liq. 2009;147(3):198-210.

23. Chiew YC. Percus-Yevick integral-equation theory for athermal hard-sphere chains, Part I: Equations of state. Mol Phys. 1990;70(1):129-143.

24. Chiew YC. Percus-Yevick integral equation theory for athermal hard-sphere chains. $\mathrm{Mol}$ Phys. 1991;73(2):359-373.

25. Yethiraj A, Hall CK, Honnell KG. Site-site correlations in short chain fluids. J Chem Phys. 1990;93(6):4453-4461. 
26. Honnell KG, Hall CK. A new equation of state for athermal chains. J Chem Phys. 1989;90(3):1841-1855.

27. Dickman R, Hall CK. Equation of state for chain molecules: Continuous-space analog of Flory theory. J Chem Phys. 1986;85(7):4108-4115.

28. Tavares FW, Chang J, Sandler SI. Equation of state for the square-well chain fluid based on the dimer version of Wertheim's perturbation theory. Mol Phys. 1995;86(6):1451-1471.

29. Kirkwood JG, Maun EK, Alder BJ. Radial distribution functions and the equation of state of a fluid composed of rigid spherical molecules. J Chem Phys. 1950;18(8):1040-1047.

30. Co KU, Kozak JJ, Luks KD. Solutions of the Yvon-Born-Green equation for the squarewell fluid at very high densities. J Chem Phys. 1976;65(6):2327-2332.

31. Lincoln WW, Kozak JJ, Luks KD. Properties of solutions to the Yvon-Born-Green equation for the square-well fluid. J Chem Phys. 1975;62(6):2171-2182.

32. Kirkwood JG, Lewinson VA, Alder BJ. Radial distribution functions and the equation of state of fluids composed of molecules interacting according to the Lennard-Jones potential. J Chem Phys. 1952;20(6):929-938.

33. Broyle AA. Radial Distribution Functions from the Born-Green Integral Equation. JChemPhys. 1960;33(2):456-458.

34. Porter J a., Fridrikh S V., Lipson JEG. Square-well chain fluids: The thermodynamic properties of hexamers, octamers, and hexadecamers. J Chem Phys. 2003;119(7):38833890.

35. Taylor MP, Luettmer-Strathmann J, Lipson JEG. Structure and phase behavior of squarewell dimer fluids. J Chem Phys. 2001;114(13):5654-5662.

36. Fridrikh S V., Lipson JEG. Square-well fluids: The statistical and thermodynamic properties of short chains. J Chem Phys. 2002;116(19):8483-8491.

37. Largo J, Solana JR, Yuste SB, Santos A. Pair correlation function of short-ranged squarewell fluids. J Chem Phys. 2005;122(8):845101-8451012.

38. Henderson D, Madden WG, Fitts DD. Monte Carlo and hypernetted chain equation of state for the square-well fluid. J Chem Phys. 1976;64:5026.

39. Scarfe KD, McLaughlin IL, Collings AF. The transport coefficients for a fluid of squarewell rough spheres: Comparison with methane. J Chem Phys. 1976;65:2991. 
40. Taylor MP. Square-well diatomics Exact low density results. Mol Phys. 1994;64:1151.

41. Taylor MP, Lipson JEG. A site-site Born-Green-Yvon equation for hard sphere dimers. $J$ Chem Phys. 1994;100:518.

42. Paredes MLL, Nobrega R, Tavares FW. Square-well chain mixture: analytic equation of state and Monte Carlo simulation data. Fluid Phase Equilib. 2001;179:245-267.

43. Allen MP, Tildesley DJ. Computer Simulation of Liquids. (University O, ed.).; 1987.

44. Paricaud P. Phase equilibria in polydisperse nonadditive hard-sphere systems. Phys Rev E Stat Nonlinear, Soft Matter Phys. 2008;78(2):1-12. 